\title{
Counter-acts : letters to the The Guardian and the Electronic Frontier Foundation.
}

\author{
Camille Akmut
}

June 13, 2019

\begin{abstract}
We trusted them, but they pulled their punches, so we punched back. A series of letters that accompanied our research.
\end{abstract}




\section{EFF}

(a)FF

Interested in the early days of hacking culture? Join us on June 18 at the @internetarchive for a book reading and panel discussion about (and with!) some of the original hacking supergroup, the Cult of the Dead Cow.

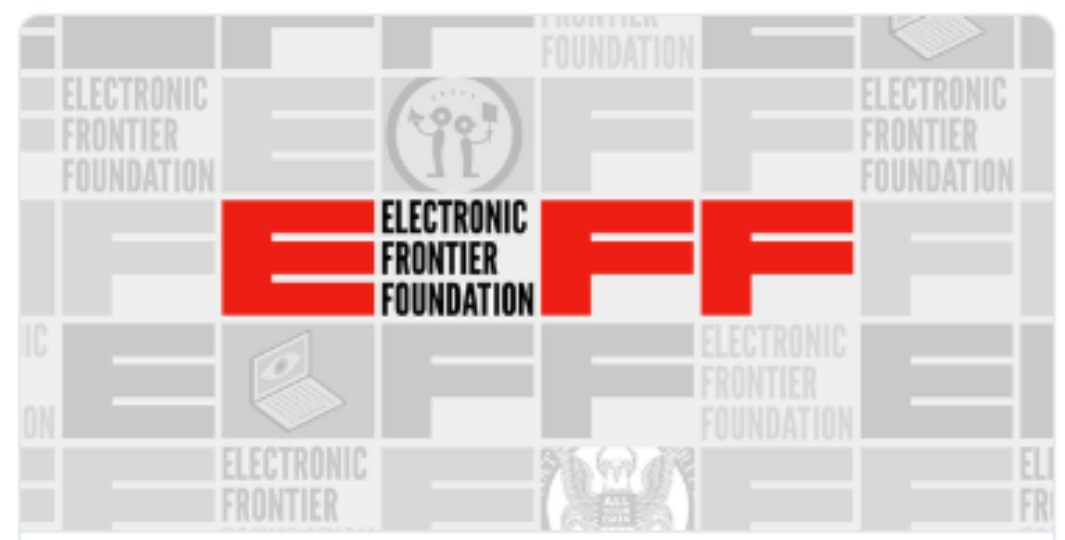

Cult of the Dead Cow Book Event at the Internet Archive

Join us on June 18, 2019 at the Internet Archive for a book reading and panel discussion about (and with!) some of the original hacking supergroup, the Cult of ... eff.org

6:20 PM - 12 Jun 2019

21 Retweets 43 Lkes 10980

$Q_{2}$ t] $21 \quad \bigcirc_{43}$ 


\section{American history does not start with the Mayflower - letter to the EFF, 13/06}

This is a feedback to your following publication :

"Interested in the early days of hacking culture? Join us on June 18 at the @internetarchive for a book reading and panel..."

https://twitter.com/EFF/status/1138979468653940736

In writing this, you're not only misguided, but contribute to propagating a harmful myth about hacking, what it is, where it comes from.

Hacking culture, contrary to what you seem to believe, started in the 1960 s at MIT, during what could be described as the first wave. It then moved to Stanford, as members of the original culture moved there (second wave).

Richard Stallman, "the last of the hackers", was part of the third or fourth wave - or so.

All of this is described at length in Steven Levy's book 'Hackers'.

In these early days, hacker was synonymous with computer scientist and electrical engineer, as hackers were mostly either or.

In this larger history, thus, of hackers, and hacking (i.e. the doing of hackers), groups such as The Cult of the Dead Cow are 10th or 12th wave hacking culture at best.

By reminding of this important history, we do not take away from them.

Equivalent to saying "Interested in the early days of American culture?" and starting with the Mayflower... 
UK World Business Football UK politics Environment Education Society Science Tech Global development Cities

\section{Philanthropy MacKenzie Bezos pledges at least half her wealth to charity}

Jeff Bezos' former wife, known as world's 22nd richest person with $\$ 36.6 \mathrm{bn}$ fortune, signs up to the Giving Pledge

Rupert Neate Wealth correspondent

v @RupertNeate

Tue 28 May 2019 12.27 EDT

f $\square$

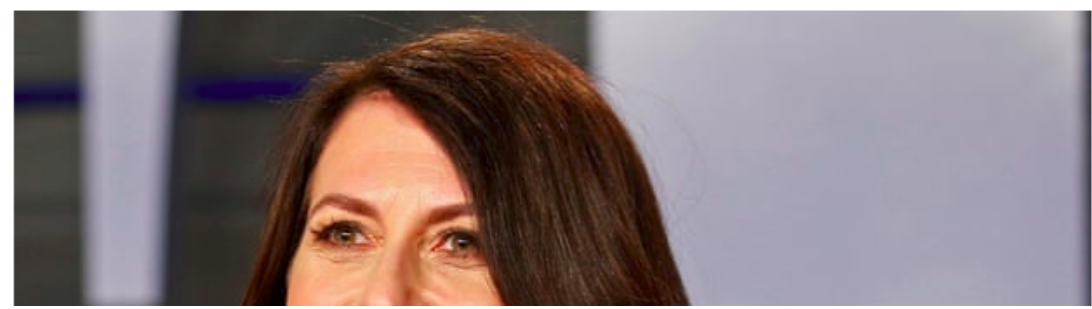




\section{"The powerful in tech" and a present-day Royal reporter - letter to The Guardian, $28 / 05$}

In this article, Rupert Neate, "Wealth correspondent" (a title so pompous it ought be changed to reporter by Royal warrant of appointment (...)), writes about ex-Mrs Bezos and her philanthropy buffoonery/schemes... His article is more or less a copy of what had appeared in Reuters earlier this morning.

But, where Reuters has the benefit of latest-of-the-latest of news, the Guardian doesn't, and more is expected of it, naturally, independently.

However, here, we find no commentary, no critic whatsoever; nothing, in other words, that would help us put these events into any kind of larger, bigger picture.

But, what kind of journalism is this?

Certainly not the one you claim to represent at the bottom of the article :

"The powerful in tech...

... must keep being challenged with bold investigative journalism."

But, the tools for you to uphold this promise are not lacking :

Historian and public intellectual Rutger Bregman had made a convincing argument a few months back at the Davos forum : that philanthropy is popular among the elite, at the forefront of which the tech elite, insofar as it represents a diversion from topics such as taxes, and linked to it economic inequalities and widening economic gaps.

But, here, in this Royal article, nothing of the sort is found, and certainly no indication as to how Mr Bezos was able to accumulate such a fortune, and by consequence his wife :

European Tax havens, 'Indian reservation' schemes, etc. etc... A fact your journalists, of the non-Royal/wealth kind, have reported on many times.

Such topics are completely lost on your audience in columns such as 'Society', and when presented by what I will call here one last time 'society journalists'. They should be handled by those journalists of yours who have a competency to do so.

This breaches none of your established guidelines, except the most important of course :

(real) journalism. 


\section{References}

—. 2019. "The Libertarian roots of the EFF."

-. 2019. "The 'human elements' in computing : an encryption fiasco at The Intercept." 